\title{
BMJ Open Associations of serum liver enzyme levels and their changes over time with all-cause and cause-specific mortality in the general population: a large-scale national health screening cohort study
}

\author{
Kyoung-Nam Kim, ${ }^{1,2}$ Jungmin Joo, ${ }^{1}$ Ho Kyung Sung, ${ }^{1}$ Chee Hae Kim, ${ }^{3}$ \\ Haebin Kim, ${ }^{1}$ Yong Jin Kwon ${ }^{1,4}$
}

To cite: Kim K-N, Joo J, Sung HK, et al. Associations of serum liver enzyme levels and their changes over time with all-cause and causespecific mortality in the general population: a large-scale national health screening cohort study. BMJ Open 2019;9:e026965. doi:10.1136/ bmjopen-2018-026965

- Prepublication history and additional material for this paper are available online. To view these files, please visit the journal online (http://dx.doi org/10.1136/bmjopen-2018026965).

Received 2 October 2018 Revised 5 March 2019 Accepted 1 April 2019
Check for updates

(C) Author(s) (or their employer(s)) 2019. Re-use permitted under CC BY-NC. No commercial re-use. See rights and permissions. Published by BMJ.

For numbered affiliations see end of article.

Correspondence to Professor Yong Jin Kwon; 301kwon@snuh.org

\section{ABSTRACT}

Objectives To investigate the associations of the levels of liver enzymes, such as alanine aminotransferase (ALT), aspartate aminotransferase (AST) and gamma glutamyltransferase (GGT), at baseline and their changes over time with mortality.

Design Cohort study.

Setting, participants and outcome measures We analysed the data of 484472 individuals from the National Health Insurance Service-National Health Screening Cohort (2002-2013). We used two exposure indices: (1) deciles of baseline ALT, AST and GGT levels measured in 2002 or 2003 and (2) deciles of changes in ALT, AST and GGT levels over a 4 year period (2002-2006 or 2003-2007). We constructed Cox models to evaluate the associations of these exposure indices with mortality (2008-2013).

Results We found non-monotonic dose-response associations between the baseline levels of ALT and AST and all-cause mortality. We also found a monotonic nonlinear association between the baseline levels of GGT and all-cause mortality (10th decile: $\mathrm{HR}=2.05,95 \% \mathrm{Cl}: 1.93$ to 2.18). Compared with the ninth, sixth and fourth deciles of changes in ALT (8-13U/L), AST (1 U/L) and GGT (-3 to $-2 \mathrm{U} / \mathrm{L}$ ) over time, respectively, the risks of all-cause mortality increased in both the higher and lower deciles of changes in the corresponding liver enzyme levels (10th decile: $\mathrm{HR}=1.36,95 \% \mathrm{Cl} 1.24$ to 1.48 ; 1 st decile: $\mathrm{HR}=1.46$, $95 \% \mathrm{Cl} 1.34$ to 1.59 for ALT; 10 th decile: $1.55,95 \% \mathrm{Cl}$ 1.40 to $1.71 ; 1$ st decile: $\mathrm{HR}=1.53,95 \% \mathrm{Cl} 1.38$ to 1.69 for AST; 10 th decile: $\mathrm{HR}=1.71,95 \% \mathrm{Cl} 1.56$ to 1.88 ; $1 \mathrm{st}$ decile: $\mathrm{HR}=1.67,95 \% \mathrm{Cl} 1.52$ to 1.84 for GGT). These nonmonotonic dose-response associations remained when analyses were stratified by the medians or quartiles of the baseline liver enzyme levels.

Conclusions The levels of liver enzymes at baseline and over time showed non-linear associations with mortality.

\section{INTRODUCTION}

Serum levels of liver enzymes, such as alanine aminotransferase (ALT), aspartate aminotransferase (AST) and gamma glutamyltransferase (GGT), are highly sensitive to liver
Strengths and limitations of this study

- First study to report non-monotonic dose-response associations between changes in liver enzyme levels over time and mortality.

- Conducted longitudinal analyses using a large-scale cohort constructed from national administration data, which has a negligible follow-up loss.

- Identified the dates and causes of death using a national database maintained by Statistics Korea, which covers all individuals residing in the Republic of Korea and has high accuracy $(>90 \%)$.

- Information on albumin, alkaline phosphatase, and conjugated and unconjugated bilirubin levels was not available, and information on sociodemographic factors, lifestyles, medical histories and family histories was insufficient.

- Could not identify the mechanisms underlying the association between liver enzyme levels and mortality.

dysfunction and damage. ${ }^{1}$ Because assays for these liver enzymes are cost-effective, they are widely used during general health check-ups worldwide. $^{23}$

Although liver enzyme levels have been associated with various health outcomes such as cardiovascular diseases, ${ }^{4}$ type 2 diabetes mellitus ${ }^{5}$ and cancer$^{6}{ }^{6}$ the associations between liver enzyme levels and mortality in the general population remained unclear. Previous studies reported positive, null and inverse associations between liver enzyme levels and mortality in the general population (reviewed by Kunutsor $e t a l^{3}$ ). The association between liver enzyme levels and mortality might not be linear, and both higher and lower liver enzyme levels would be associated with higher mortality (ie, non-monotonic dose-response associations). Although we expected the non-monotonic dose-response 
associations between liver enzyme levels and mortality, this possibility has only been investigated in a limited number of studies. ${ }^{378}$

Liver enzyme levels can increase due to factors such as liver damage and injury, and can decrease due to factors such as hepatic ageing, frailty and reduced hepatic blood circulation. ${ }^{9} 10$ Therefore, changes (increases or decreases) in the levels of these enzymes over time may be associated with higher mortality independent of baseline liver enzyme levels. However, to our knowledge, no study has explored the possibility of non-monotonic doseresponse associations between changes in liver enzyme levels over time and mortality.

Therefore, in the present study, we hypothesised that not only higher baseline liver enzyme levels but also lower baseline levels are associated with higher mortality. In addition, we hypothesised that the increase or decrease in liver enzyme levels over time is also associated with higher mortality independent of baseline liver enzyme levels. We evaluated these hypotheses using a longitudinal study design with a large-scale $(n>500000)$ national health screening cohort in which serum liver enzyme levels were repeatedly measured.

\section{METHODS}

\section{Study population}

The present study used data from the National Health Insurance Service-National Health Screening Cohort (NHIS-HEALS) of the Republic of Korea. Detailed information on the NHIS-HEALS has been presented elsewhere. ${ }^{11}$ Briefly, the NHIS-HEALS is a de-identified cohort released to researchers by the NHIS for the purpose of public research. Several epidemiological studies have been published using these data. ${ }^{12-14}$ The NHIS-HEALS contains the data of 514866 individuals, representing a $10 \%$ random sample of all participants in the National Health Screening Program between 2002 and 2003 (data collected during this period comprise the baseline) who were followed up to 31 December 2013. In the Republic of Korea, all individuals aged $\geq 40$ years are invited to participate at least every 2 years in this general, free-of-charge health screening programme conducted at designated healthcare institutions that meet the quality standards set by the Framework Act on Health Examinations. The rate of participation in the National Health Screening Program was $43.2 \%$ in 2003 and increased gradually to
$74.8 \%$ in $2014 .{ }^{14}$ The prevalence rates of common diseases such as hypertension and type 2 diabetes mellitus in the NHIS-HEALS are generally similar to those reported in a nationally representative sample. ${ }^{11}$

The NHIS-HEALS includes various types of information, such as sociodemographic factors, lifestyles, medical histories and family histories (collected from self-reported questionnaires during the national health screening), health screening results (from physical examinations and clinical laboratory tests during the national health screening), healthcare usage (from claims data), and dates and causes of death (from Statistics Korea).

In the present study, from a total of 514866 individuals included in the NHIS-HEALS, we sequentially excluded those who died between 2002 and 2007 ( $\mathrm{n}=13278,2.6 \%$ ), those without any liver enzyme data between 2002 and $2003(\mathrm{n}=494,0.1 \%)$ and those with hepatitis or chronic liver disease up to $2007(\mathrm{n}=16622,3.2 \%)$. Therefore, 484472 individuals $(94.1 \%)$ were included in the final analysis. All experiments were conducted in accordance with the relevant guidelines and regulations.

\section{Patient and public involvement}

Patients were not recruited or involved in this study.

\section{Exposures}

We used two exposure indices: (1) deciles of the baseline levels of ALT, AST and GGT measured in 2002 or 2003 and (2) deciles of changes in the ALT, AST and GGT levels over a 4-year period (2002-2006 or 2003-2007) (figure 1). The first exposure index was used in an analysis of the association between baseline liver enzyme levels and mortality, while the second was used in an analysis of the association between changes in liver enzyme levels and mortality. If both the earlier and later exposure indices were available, the latter (baseline liver enzyme levels in 2003 or changes in liver enzyme levels between 2003 and 2007) was assigned as the exposure index for each individual.

\section{Outcomes}

The outcomes of the present study were all-cause mortality and cause-specific mortality occurring between 1 January 2008 and 31 December 2013 (figure 1). Information on the dates and causes of death was obtained from Statistics Korea and merged with other data by the NHIS via personal identification numbers. The various

\begin{tabular}{|c|c|c|c|c|c|c|c|c|c|c|c|c|}
\hline Year & 2002 & 2003 & 2004 & 2005 & 2006 & 2007 & 2008 & 2009 & 2010 & 2011 & 2012 & 2013 \\
\hline $\begin{array}{c}\text { Exposure 1: } \\
\text { Baseline Live } \\
\text { Enzyme }\end{array}$ & & & & & & & & & & & & \\
\hline $\begin{array}{l}\text { Exposure 2: } \\
\text { Liver Enzym } \\
\text { Change }\end{array}$ & & & & & $\Rightarrow$ & & & & & & & \\
\hline $\begin{array}{l}\text { Outcome: } \\
\text { Mortality }\end{array}$ & & & & & & & & & & & & \\
\hline
\end{tabular}

Figure 1 Schematic representation of the study design and period. 
causes of death were coded according to the International Classification of Disease, 10th Revision (ICD-10). For this analysis, we considered deaths from cardiovascular disease (defined as ICD-10 codes I20-I25, I50 and I60-I70), cancer (C00-C97), diabetes mellitus (E10-E14) and liver disease (B15-B19 and K70-K77), according to previous studies. ${ }^{7815}$

\section{Covariates}

Based on previous reports and existing biomedical knowledge, ${ }^{37-9}{ }^{15-17}$ we identified the following potential confounders and included them as covariates for further analyses: age (years), sex, household income (decile), smoking status (non-smoker, ex-smoker or smoker), alcohol consumption (none, $\leq 1-2$ or $\geq 3-4$ times/week), physical activity (did not exercise, $\leq 1-2$ or $\geq 3-4$ times/ week), body mass index $(<18.5,18.5-22.9,23.0-24.9,25.0-$ 29.9 or $\left.\geq 30.0 \mathrm{~kg} / \mathrm{m}^{2}\right)$, systolic blood pressure $(<120.0$, $120.0-139.9$ or $\geq 140.0 \mathrm{~mm} \mathrm{Hg}$ ), diastolic blood pressure $(<80.0,80.0-89.9$ or $\geq 90.0 \mathrm{~mm} \mathrm{Hg})$, fasting glucose levels $(<70.0,70.0-99.9,100.0-125.9$ or $\geq 126.0 \mathrm{~mm} \mathrm{Hg})$, history of heart disease (yes or no), history of stroke (yes or no) and history of cancer (yes or no). Information about these variables was collected from the National Health Screening Program at baseline (2002-2003). We created a missing indicator category for the missing values $(0.03 \%-$ $3.4 \%$ ) of the categorical variables (table 1 ).

\section{Statistical analysis}

We constructed Cox proportional hazard models adjusted for the above-mentioned covariates to investigate the associations of exposure indices (deciles of baseline liver enzyme levels and deciles of changes in liver enzyme levels) with all-cause mortality. Since the associations between changes in liver enzyme levels and mortality may differ according to the baseline liver enzyme levels, we also divided the study population into those with values above and below the medians or quartiles of the baseline levels of ALT, AST and GGT. We then assessed the associations between deciles of changes in the liver enzyme levels and all-cause mortality in each stratum.

We evaluated the non-linearity of the associations (non-monotonic dose-response or monotonic non-linear associations) by (1) visually inspecting the shapes of the associations in the analysis using categorised exposure indices and (2) testing the squared terms of the log2-transformed continuous baseline or changes in liver enzyme levels that were added to Cox models including the log2-transformed baseline or changes in liver enzyme levels and the same covariates.

To evaluate the associations of deciles of the baseline and changes in liver enzyme levels with cause-specific mortality (ie, deaths from cardiovascular disease, cancer, diabetes mellitus and liver disease), we constructed cause-specific proportional hazard models adjusted for the same covariates. In these competing risk analyses, we estimated cause-specific hazards rather than subdistribution hazards, because the HRs from cause-specific proportional hazard models would be easily interpretable and could be used to draw public health implications. ${ }^{18} 19$

In a sensitivity analysis, because distributions of liver enzyme levels were different by sex (U/L, ALT: median, 25, IQR, 16, among men; median, 18, IQR, 10, among women; AST: median, 25, IQR, 11, among men; median, 22, IQR, 9, among women; GGT: median, 33, IQR, 34, among men; median, 16, IQR, 12, among women), we repeated all analyses using sex-specific cut-off points for deciles of the baseline liver enzyme levels and changes in liver enzyme levels, instead of the above-mentioned sex-non-specific cut-off points, to confirm the robustness of the results. ${ }^{7}$ Detailed information on the sex-specific cut-off points is presented in the online supplementary material. In addition, we also conducted analyses further excluding individuals with a history of cancer, those with a history of type 2 diabetes mellitus and those who drank alcohol $\geq 3-4$ times/week, because these conditions can also impact liver enzyme levels.

In both the Cox and cause-specific proportional hazard models, the follow-up duration was calculated in months from 1 January 2008 to the date of death or 31 December 2013 (if death did not occur). For analyses using categorised exposure indices, we designated categories with the lowest betas for each outcome of interest in the association analysis as the referent categories. We used SAS V.9.4 for all analyses.

\section{RESULTS}

Of the 484472 study participants, the mean age was 53.0 years (range: $40-80$ years), and $53.3 \%$ were men. A larger proportion of participants had higher income levels (household income deciles $9-10,33.3 \%$ vs deciles $0-2,15.9 \%)$. A majority of the study participants were non-smokers $(65.5 \%)$, did not drink alcohol $(56.1 \%)$ and did not exercise regularly (55.8\%). Most participants had no history of heart disease, stroke or cancer (table 1).

Compared with the fourth decile of baseline ALT levels $(17-18 \mathrm{U} / \mathrm{L})$, the risk of all-cause mortality was higher in both the higher and lower baseline ALT deciles (10th decile, $\geq 43 \mathrm{U} / \mathrm{L}: \mathrm{HR}=1.53$, 95\% CI 1.44 to 1.62 ; 1st decile, $\leq 12 \mathrm{U} / \mathrm{L}: \mathrm{HR}=1.16$, 95\% CI 1.10 to 1.23$)$. Similarly, compared with the fourth decile of baseline AST levels $(21 \mathrm{U} / \mathrm{L})$, the risk of all-cause mortality was also higher in both the higher and lower baseline AST deciles (10th decile $\geq 38 \mathrm{U} / \mathrm{L}$ : HR $=1.70$, 95\% CI 1.59 to 1.81; 1 st decile, $\leq 16 \mathrm{U} / \mathrm{L}: \mathrm{HR}=1.15,95 \%$ CI 1.07 to 1.24 ). When compared with the first decile of baseline GGT levels $(\leq 11 \mathrm{U} / \mathrm{L})$, the all-cause mortality risk was higher in higher baseline GGT deciles (10th decile, $\geq 72 \mathrm{U} / \mathrm{L}$ : $\mathrm{HR}=2.05,95 \%$ CI 1.93 to 2.18) (table 2). Because the normal range of ALT is generally considered as $7-56 \mathrm{U} / \mathrm{L}$, AST as $0-35 \mathrm{U} / \mathrm{L}$ and GGT as $9-85 \mathrm{U} / \mathrm{L},{ }^{2}$ even within the normal range, lower or higher levels of ALT and AST and higher levels of GGT were associated with a higher mortality risk (table 2). We confirmed the non-linearity of these associations by testing the squared terms of the 
Table 1 Baseline sociodemographic characteristics and liver enzyme levels of the study participants (2002-2003) $(n=484472)$

\begin{tabular}{cllll}
\hline Characteristics & Total & ALT (U/L) & AST (U/L) & GGT (U/L) \\
\hline Age (years) & $\mathrm{n}(\%)$ & GM \pm GSD & & \\
$40-49$ & & & & \\
$50-59$ & $212004(43.8)$ & $21.8 \pm 1.7$ & $23.5 \pm 1.4$ & $26.1 \pm 2.2$ \\
$60-69$ & $140742(29.1)$ & $22.8 \pm 1.6$ & $24.9 \pm 1.4$ & $26.8 \pm 2.1$ \\
$70-80$ & $98759(20.4)$ & $21.6 \pm 1.6$ & $25.4 \pm 1.4$ & $21.6 \pm 2.0$ \\
Sex & $32967(6.8)$ & $19.5 \pm 1.6$ & $25.2 \pm 1.4$ & \\
Men & & & & $35.8 \pm 2.1$ \\
Women & $258010(53.3)$ & $25.3 \pm 1.7$ & $26.1 \pm 1.5$ & $17.6 \pm 1.8$
\end{tabular}

Household income (deciles)

\begin{tabular}{|c|c|c|c|c|}
\hline $0-2$ & 76994 (15.9) & $20.8 \pm 1.7$ & $24.2 \pm 1.4$ & $23.7 \pm 2.1$ \\
\hline $3-5$ & 106260 (21.9) & $21.6 \pm 1.7$ & $24.7 \pm 1.5$ & $25.1 \pm 2.1$ \\
\hline $6-8$ & $139763(28.9)$ & $22.4 \pm 1.7$ & $24.7 \pm 1.4$ & $26.6 \pm 2.1$ \\
\hline $9-10$ & 161455 (33.3) & $22.2 \pm 1.7$ & $24.0 \pm 1.4$ & $26.2 \pm 2.1$ \\
\hline \multicolumn{5}{|l|}{ Smoking status } \\
\hline Non-smoker & 317199 (65.5) & $20.5 \pm 1.6$ & $23.6 \pm 1.4$ & $21.4 \pm 1.9$ \\
\hline Ex-smoker & 40797 (8.4) & $25.4 \pm 1.7$ & $25.8 \pm 1.4$ & $34.1 \pm 2.0$ \\
\hline Smoker & $109868(22.7)$ & $25.0 \pm 1.7$ & $26.0 \pm 1.5$ & $39.0 \pm 2.1$ \\
\hline Missing & $16608(3.4)$ & $22.0 \pm 1.7$ & $24.6 \pm 1.4$ & $25.4 \pm 2.1$ \\
\hline \multicolumn{5}{|l|}{ Alcohol consumption } \\
\hline None & 271551 (56.1) & $20.4 \pm 1.6$ & $23.2 \pm 1.4$ & $20.1 \pm 1.8$ \\
\hline$\leq 1-2$ times/week & 151559 (31.3) & $23.4 \pm 1.7$ & $24.9 \pm 1.4$ & $31.4 \pm 2.1$ \\
\hline$\geq 3-4$ times/week & $53350(11.0)$ & $25.9 \pm 1.7$ & $28.9 \pm 1.5$ & $51.1 \pm 2.3$ \\
\hline Missing & $8012(1.7)$ & $20.9 \pm 1.6$ & $23.5 \pm 1.4$ & $21.0 \pm 1.9$ \\
\hline \multicolumn{5}{|l|}{ Physical activity } \\
\hline Did not exercise & 270329 (55.8) & $21.4 \pm 1.7$ & $24.3 \pm 1.4$ & $24.5 \pm 2.1$ \\
\hline$\leq 1-2$ times/week & $112413(23.2)$ & $23.0 \pm 1.7$ & $24.5 \pm 1.4$ & $28.5 \pm 2.1$ \\
\hline$\geq 3-4$ times/week & $89843(18.5)$ & $21.9 \pm 1.6$ & $24.4 \pm 1.4$ & $25.9 \pm 2.1$ \\
\hline Missing & $11887(2.5)$ & $21.7 \pm 1.7$ & $25.4 \pm 1.4$ & $25.2 \pm 2.1$ \\
\hline \multicolumn{5}{|c|}{ Body mass index $\left(\mathrm{kg} / \mathrm{m}^{2}\right)$} \\
\hline$<18.5$ & $10599(2.2)$ & $17.7 \pm 1.6$ & $24.6 \pm 1.5$ & $21.1 \pm 2.2$ \\
\hline $18.5-22.9$ & $171108(35.3)$ & $19.1 \pm 1.6$ & $23.4 \pm 1.4$ & $21.9 \pm 2.1$ \\
\hline $23.0-24.9$ & $132394(27.3)$ & $21.9 \pm 1.6$ & $24.0 \pm 1.4$ & $25.9 \pm 2.1$ \\
\hline $25.0-29.9$ & $156051(32.2)$ & $25.1 \pm 1.7$ & $25.5 \pm 1.4$ & $30.1 \pm 2.1$ \\
\hline$\geq 30.0$ & $13926(2.9)$ & $29.0 \pm 1.8$ & $27.6 \pm 1.5$ & $32.1 \pm 2.1$ \\
\hline Missing & $394(0.1)$ & $21.4 \pm 1.6$ & $24.6 \pm 1.4$ & $22.2 \pm 2.0$ \\
\hline \multicolumn{5}{|c|}{$\begin{array}{l}\text { Systolic blood pressure } \\
(\mathrm{mm} \mathrm{Hg})\end{array}$} \\
\hline$<120.0$ & $140993(29.1)$ & $19.7 \pm 1.6$ & $22.8 \pm 1.4$ & $21.1 \pm 2.0$ \\
\hline $120.0-139.9$ & $214824(44.3)$ & $22.3 \pm 1.7$ & $24.5 \pm 1.4$ & $26.4 \pm 2.1$ \\
\hline$\geq 140.0$ & $128464(26.5)$ & $23.7 \pm 1.7$ & $26.0 \pm 1.5$ & $30.4 \pm 2.2$ \\
\hline Missing & $191(0.04)$ & $21.1 \pm 1.7$ & $23.3 \pm 1.5$ & $24.4 \pm 2.0$ \\
\hline \multicolumn{5}{|c|}{$\begin{array}{l}\text { Diastolic blood pressure } \\
(\mathrm{mm} \mathrm{Hg})\end{array}$} \\
\hline$<80.0$ & $191221(39.5)$ & $20.1 \pm 1.6$ & $23.2 \pm 1.4$ & $21.7 \pm 2.0$ \\
\hline
\end{tabular}

Continued 


\begin{tabular}{|c|c|c|c|c|}
\hline Characteristics & Total & ALT (U/L) & AST (U/L) & GGT (U/L) \\
\hline $80.0-89.9$ & $167612(34.6)$ & $22.4 \pm 1.7$ & $24.6 \pm 1.4$ & $26.6 \pm 2.1$ \\
\hline$\geq 90.0$ & $125372(25.9)$ & $24.2 \pm 1.7$ & $26.0 \pm 1.5$ & $31.5 \pm 2.2$ \\
\hline Missing & $267(0.1)$ & $21.5 \pm 1.7$ & $23.4 \pm 1.4$ & $23.8 \pm 2.0$ \\
\hline \multicolumn{5}{|c|}{$\begin{array}{l}\text { Fasting glucose level } \\
(\mathrm{mg} / \mathrm{dL})\end{array}$} \\
\hline$<70.0$ & $8510(1.8)$ & $20.3 \pm 1.7$ & $23.9 \pm 1.4$ & $23.2 \pm 2.0$ \\
\hline $70.0-99.9$ & 324064 (66.9) & $20.9 \pm 1.6$ & $23.9 \pm 1.4$ & $23.7 \pm 2.0$ \\
\hline $100.0-125.9$ & $114597(23.7)$ & $23.6 \pm 1.7$ & $25.3 \pm 1.5$ & $29.1 \pm 2.2$ \\
\hline$\geq 126.0$ & $37167(7.7)$ & $26.5 \pm 1.7$ & $26.1 \pm 1.6$ & $35.9 \pm 2.3$ \\
\hline Missing & $134(0.03)$ & $19.7 \pm 1.7$ & $22.8 \pm 1.7$ & $20.7 \pm 2.0$ \\
\hline \multicolumn{5}{|c|}{ History of heart disease } \\
\hline No & 494401 (98.6) & $21.9 \pm 1.7$ & $24.4 \pm 1.4$ & $25.6 \pm 2.1$ \\
\hline Yes & $7187(1.4)$ & $22.4 \pm 1.6$ & $25.0 \pm 1.4$ & $26.3 \pm 2.0$ \\
\hline \multicolumn{5}{|l|}{ History of stroke } \\
\hline No & 499352 (99.6) & $21.9 \pm 1.7$ & $24.4 \pm 1.4$ & $25.7 \pm 2.1$ \\
\hline Yes & $2236(0.5)$ & $22.0 \pm 1.6$ & $24.6 \pm 1.4$ & $27.4 \pm 2.0$ \\
\hline \multicolumn{5}{|l|}{ History of cancer } \\
\hline No & $498856(99.5)$ & $21.9 \pm 1.7$ & $24.4 \pm 1.4$ & $25.7 \pm 2.1$ \\
\hline Yes & $2732(0.5)$ & $20.7 \pm 1.6$ & $25.0 \pm 1.4$ & $21.2 \pm 1.9$ \\
\hline
\end{tabular}

ALT, alanine aminotransferase; AST, aspartate aminotransferase; GGT, gamma glutamyltransferase; GM, geometric mean; GSD, geometric SD

log2-transformed ALT, AST and GGT levels added to the Cox models (all $\mathrm{p}$ values for the squared terms $<0.0001$ ).

We also assessed the associations of deciles of changes in the liver enzyme levels over a 4-year period with all-cause mortality. Compared with the ninth decile of ALT changes (8-13 U/L), the sixth decile of AST changes $(1 \mathrm{U} / \mathrm{L})$, and the fourth decile of GGT changes ( -3 to $-2 \mathrm{U} / \mathrm{L})$, respectively, the risk of all-cause mortality was higher in both the higher and lower deciles of changes in the corresponding liver enzyme levels (10th decile, $\geq 14$ $\mathrm{U} / \mathrm{L}: \mathrm{HR}=1.36,95 \%$ CI 1.24 to 1.48 ; 1 st decile, $\leq-16 \mathrm{U} / \mathrm{L}$ : $\mathrm{HR}=1.46,95 \%$ CI 1.34 to 1.59 for ALT; 10th decile, $\geq 11$ $\mathrm{U} / \mathrm{L}: \mathrm{HR}=1.55,95 \%$ CI 1.40 to 1.71 ; 1 st decile, $\leq-12 \mathrm{U} / \mathrm{L}$ : $\mathrm{HR}=1.53,95 \%$ CI 1.38 to 1.69 for AST; 10th decile, $\geq 21$ $\mathrm{U} / \mathrm{L}: \mathrm{HR}=1.71,95 \%$ CI 1.56 to 1.88 ; 1 st decile, $\leq-19 \mathrm{U} / \mathrm{L}$ : $\mathrm{HR}=1.67,95 \%$ CI 1.52 to 1.84 for GGT) (table 3 ). We then tested the squared terms of the log2-transformed changes in ALT, AST and GGT and confirmed the non-linearity of the associations between the changes in liver enzyme levels and mortality (all $\mathrm{p}$ values for the squared terms $<0.0001$ ).

When we performed stratified analyses by the medians or quartiles of the baseline liver enzyme levels, the same non-monotonic dose-response associations between the deciles of changes in liver enzyme levels and all-cause mortality remained in each stratum (figure 2, online supplementary figure 1), similar to the results of the non-stratified analysis (table 3 ).
In analyses of the associations between the deciles of baseline liver enzyme levels and cause-specific mortality (mortality due to cardiovascular disease, cancer, diabetes mellitus and liver disease), we found non-monotonic dose-response associations of baseline ALT and AST levels with mortality due to cardiovascular disease, cancer and diabetes mellitus, whereas we found monotonic non-linear associations in other cases (online supplementary figure 2). When we analysed the associations between the deciles of changes in the liver enzyme levels and cause-specific mortality, we found non-monotonic doseresponse associations in all cases (online supplementary figure 3).

In sensitivity analyses based on sex-specific deciles of the baseline and changes in liver enzyme levels, the results remained robust and did not change appreciably (data not shown). When we excluded individuals with a history of cancer $(n=2732)$, those with a history of type 2 diabetes mellitus $(\mathrm{n}=20691)$ and those who drank $\geq 3-4$ times/week $(n=53350)$, the results did not change appreciably (data not shown).

\section{DISCUSSION}

In the present study, using the large-scale national health screening cohort, we found non-linear (non-monotonic dose-response or monotonic non-linear) associations of baseline liver enzyme levels and changes in these levels 
Table 2 Associations* between baseline liver enzyme levels (2002-2003) and all-cause mortality (2008-2013)

\begin{tabular}{|c|c|c|c|c|c|}
\hline Decilet & Levels (U/L) & n (\%) & HR & $95 \% \mathrm{Cl}$ & $P$ value \\
\hline \multicolumn{6}{|l|}{ ALT } \\
\hline 1 & $\leq 12$ & $56870(11.7)$ & 1.16 & 1.10 to 1.23 & $<0.0001$ \\
\hline 2 & $13-14$ & $41904(8.7)$ & 1.11 & 1.04 to 1.17 & 0.0014 \\
\hline 3 & $15-16$ & $46115(9.5)$ & 1.07 & 1.01 to 1.13 & 0.0292 \\
\hline 4 & $17-18$ & $46272(9.6)$ & Ref. & Ref. & Ref. \\
\hline 5 & $19-21$ & $62738(13.0)$ & 1.06 & 1.01 to 1.12 & 0.0320 \\
\hline 6 & $22-23$ & $33898(7.0)$ & 1.04 & 0.97 to 1.11 & 0.2722 \\
\hline 7 & $24-27$ & 54157 (11.2) & 1.05 & 0.99 to 1.11 & 0.1046 \\
\hline 8 & 28-32 & $46873(9.7)$ & 1.11 & 1.05 to 1.18 & 0.0005 \\
\hline 9 & $33-42$ & 49009 (10.1) & 1.17 & 1.10 to 1.24 & $<0.0001$ \\
\hline 10 & $\geq 43$ & $46601(9.6)$ & 1.53 & 1.44 to 1.62 & $<0.0001$ \\
\hline \multicolumn{6}{|l|}{ AST } \\
\hline 1 & $\leq 16$ & $48178(10.0)$ & 1.15 & 1.07 to 1.24 & 0.0001 \\
\hline 2 & $17-18$ & $45357(9.4)$ & 1.09 & 1.01 to 1.18 & 0.0217 \\
\hline 3 & $19-20$ & $58461(12.1)$ & 1.09 & 1.02 to 1.17 & 0.0175 \\
\hline 4 & 21 & $30304(6.3)$ & Ref. & Ref. & Ref. \\
\hline 5 & $22-23$ & $58761(12.1)$ & 1.03 & 0.96 to 1.10 & 0.4151 \\
\hline 6 & $24-25$ & $52190(10.8)$ & 1.06 & 0.99 to 1.14 & 0.0896 \\
\hline 7 & $26-27$ & $41805(8.6)$ & 1.09 & 1.01 to 1.17 & 0.0185 \\
\hline 8 & $28-31$ & $58055(12.0)$ & 1.08 & 1.01 to 1.15 & 0.0257 \\
\hline 9 & $32-37$ & 44515 (9.2) & 1.20 & 1.12 to 1.28 & $<0.0001$ \\
\hline 10 & $\geq 38$ & $46802(9.7)$ & 1.70 & 1.59 to 1.81 & $<0.0001$ \\
\hline \multicolumn{6}{|l|}{ GGT } \\
\hline 1 & $\leq 11$ & $54316(11.2)$ & Ref. & Ref. & Ref. \\
\hline 2 & $12-13$ & $36355(7.5)$ & 1.01 & 0.94 to 1.08 & 0.7713 \\
\hline 3 & $14-16$ & $55121(11.4)$ & 1.07 & 1.00 to 1.13 & 0.0412 \\
\hline 4 & $17-19$ & $49756(10.3)$ & 1.10 & 1.04 to 1.17 & 0.0019 \\
\hline 5 & 20-23 & $53476(11.0)$ & 1.12 & 1.06 to 1.19 & 0.0002 \\
\hline 6 & $24-27$ & $41003(8.5)$ & 1.16 & 1.09 to 1.24 & $<0.0001$ \\
\hline 7 & 28-34 & $50696(10.5)$ & 1.24 & 1.17 to 1.32 & $<0.0001$ \\
\hline 8 & $35-45$ & $48116(9.9)$ & 1.31 & 1.23 to 1.39 & $<0.0001$ \\
\hline 9 & $46-71$ & $49144(10.1)$ & 1.46 & 1.37 to 1.55 & $<0.0001$ \\
\hline 10 & $\geq 72$ & $46450(9.6)$ & 2.05 & 1.93 to 2.18 & $<0.0001$ \\
\hline
\end{tabular}

*Adjusted for age, sex, household income decile, smoking status, alcohol consumption, physical activity, body mass index, systolic blood pressure and diastolic blood pressure, fasting glucose levels, and history of heart disease, stroke and cancer. †Deciles for baseline levels of ALT, AST and GGT.

ALT, alanine aminotransferase; AST, aspartate aminotransferase; GGT, gamma glutamyltransferase; Ref., reference.

over time with both all-cause mortality and cause-specific mortality. The non-monotonic dose-response associations between changes in the liver enzyme levels and mortality remained after stratifying the study population into subgroups according to the baseline liver enzyme levels.

Although some previous studies have reported inverse associations between ALT levels and all-cause mortality, ${ }^{9} 1720$ other studies have demonstrated positive associations. ${ }^{21}{ }^{22}$ Similarly, some studies have described positive associations between AST levels and all-cause mortality, ${ }^{21} 2324$ whereas other studies found no such associations. ${ }^{25}{ }^{26}$ This heterogeneity may be explained by the increased risk of mortality associated with both higher and lower baseline levels of ALT and AST (non-monotonic dose-response associations), as demonstrated in the present study. ${ }^{378}$ Meanwhile, most previous studies have reported positive associations between baseline GGT levels and all-cause mortality. ${ }^{15} 17$ The results of the present study, which suggest the presence of a monotonic 
Open access

Table 3 Associations* between changes in liver enzyme levels since the baseline survey (2002-2003) and all-cause mortality (2008-2013)

\begin{tabular}{|c|c|c|c|c|c|}
\hline Decilet & Levels (U/L) & n (\%) & HR & $95 \% \mathrm{Cl}$ & $P$ value \\
\hline \multicolumn{6}{|l|}{ ALT } \\
\hline 1 & $\leq-16$ & 28441 (9.6) & 1.46 & 1.34 to 1.59 & $<0.0001$ \\
\hline 2 & -15 to -9 & $29670(10.0)$ & 1.23 & 1.13 to 1.34 & $<0.0001$ \\
\hline 3 & -8 to -5 & 34065 (11.4) & 1.11 & 1.02 to 1.21 & 0.0137 \\
\hline 4 & -4 to -3 & $23295(7.8)$ & 1.08 & 0.98 to 1.18 & 0.1334 \\
\hline 5 & -2 to -1 & 27637 (9.3) & 1.12 & 1.03 to 1.23 & 0.0127 \\
\hline 6 & $0-1$ & $28738(9.7)$ & 1.11 & 1.02 to 1.22 & 0.0226 \\
\hline 7 & $2-4$ & 38771 (13.0) & 1.02 & 0.94 to 1.12 & 0.5916 \\
\hline 8 & $5-7$ & $27754(9.3)$ & 1.01 & 0.92 to 1.11 & 0.8602 \\
\hline 9 & $8-13$ & $29713(10.0)$ & Ref. & Ref. & Ref. \\
\hline 10 & $\geq 14$ & $29842(10.0)$ & 1.36 & 1.24 to 1.48 & $<0.0001$ \\
\hline \multicolumn{6}{|l|}{ AST } \\
\hline 1 & $\leq-12$ & 27631 (9.3) & 1.53 & 1.38 to 1.69 & $<0.0001$ \\
\hline 2 & -11 to -7 & $29839(10.0)$ & 1.23 & 1.11 to 1.36 & 0.0001 \\
\hline 3 & -6 to -4 & 33587 (11.3) & 1.09 & 0.98 to 1.21 & 0.1081 \\
\hline 4 & -3 to -2 & $30433(10.2)$ & 1.15 & 1.03 to 1.28 & 0.0113 \\
\hline 5 & -1 to 0 & 35094 (11.8) & 1.10 & 0.99 to 1.22 & 0.0773 \\
\hline 6 & 1 & 17637 (5.9) & Ref. & Ref. & Ref. \\
\hline 7 & $2-3$ & $32282(10.8)$ & 1.02 & 0.92 to 1.14 & 0.7010 \\
\hline 8 & $4-6$ & 36128 (12.1) & 1.05 & 0.95 to 1.17 & 0.3479 \\
\hline 9 & $7-10$ & 26425 (8.9) & 1.04 & 0.93 to 1.16 & 0.4996 \\
\hline 10 & $\geq 11$ & $28874(9.7)$ & 1.55 & 1.40 to 1.71 & $<0.0001$ \\
\hline \multicolumn{6}{|l|}{ GGT } \\
\hline 1 & $\leq-19$ & 28402 (9.5) & 1.67 & 1.52 to 1.84 & $<0.0001$ \\
\hline 2 & -18 to -9 & 28240 (9.5) & 1.15 & 1.05 to 1.27 & 0.0043 \\
\hline 3 & -8 to -4 & 35442 (11.9) & 1.09 & 0.99 to 1.20 & 0.0931 \\
\hline 4 & -3 to -2 & $22232(7.5)$ & Ref. & Ref. & Ref. \\
\hline 5 & -1 to 1 & $41200(13.8)$ & 1.01 & 0.92 to 1.12 & 0.7703 \\
\hline 6 & $2-3$ & 26555 (8.9) & 1.00 & 0.90 to 1.12 & 0.9599 \\
\hline 7 & $4-6$ & $31623(10.6)$ & 1.10 & 1.00 to 1.21 & 0.0602 \\
\hline 8 & $7-10$ & $26769(9.0)$ & 1.07 & 0.96 to 1.18 & 0.2187 \\
\hline 9 & $11-20$ & 28416 (9.5) & 1.22 & 1.11 to 1.35 & $<0.0001$ \\
\hline 10 & $\geq 21$ & 29297 (9.8) & 1.71 & 1.56 to 1.88 & $<0.0001$ \\
\hline
\end{tabular}

*Adjusted for age, sex, household income decile, smoking status, alcohol consumption, physical activity, body mass index, systolic blood pressure and diastolic blood pressure, fasting glucose levels, and history of heart disease, stroke and cancer.

†Deciles for changes in levels of ALT, AST and GGT during the 4 years since the baseline survey.

ALT, alanine aminotransferase; AST, aspartate aminotransferase; GGT, gamma glutamyltransferase; Ref., reference.

non-linear association between the baseline GGT levels and all-cause mortality, may explain those earlier findings.

It has been reported that serum ALT, AST and GGT levels are associated with a higher risk of type 2 diabetes mellitus and body mass index even within the normal ranges. ${ }^{27}$ In the present study, liver enzyme levels within normal ranges were also found to be associated with mortality. Because the liver is a central organ of glucose and lipid metabolism and critical for maintaining health, ${ }^{28}$ re-evaluation of the relevance of current standards is warranted.

In the present study, larger changes (both increases and decreases) in the ALT, AST and GGT levels over a 4-year period were associated with a higher risk of all-cause mortality when compared with smaller changes. These non-linear associations remained even after the participants were stratified according to the baseline liver enzyme levels. These results suggest that changes in liver 


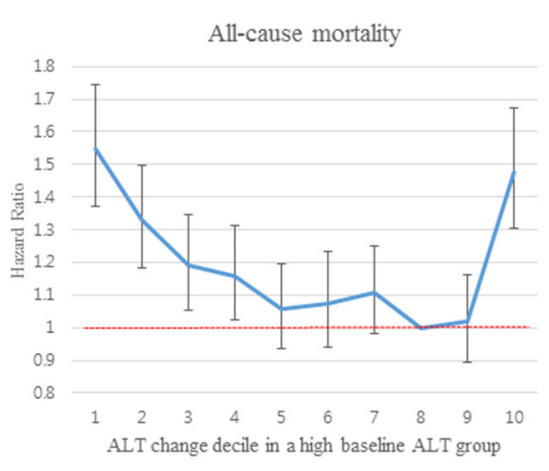

All-cause mortality

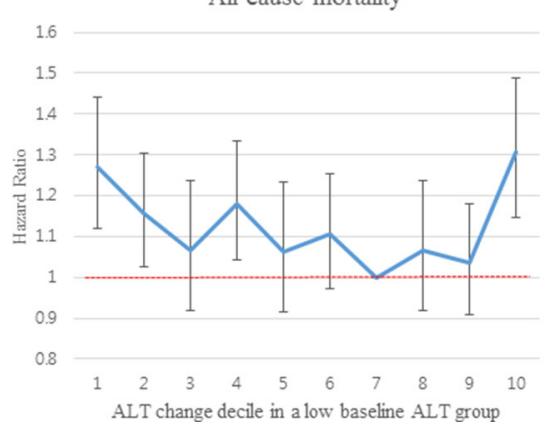

All-cause mortality

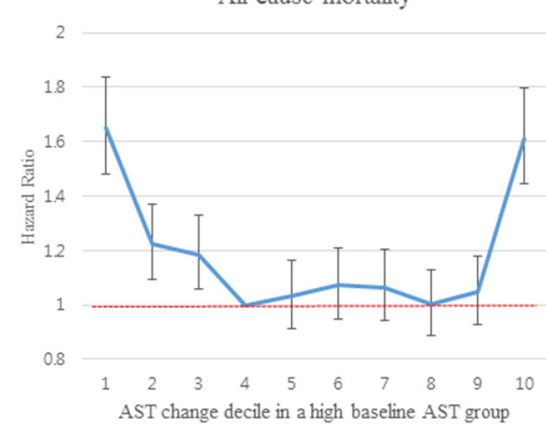

All-cause mortality

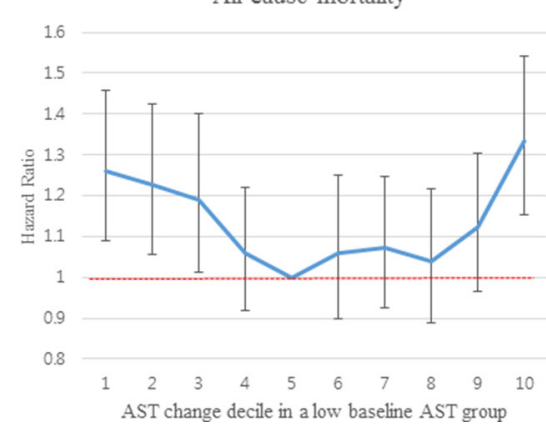

All-cause mortality

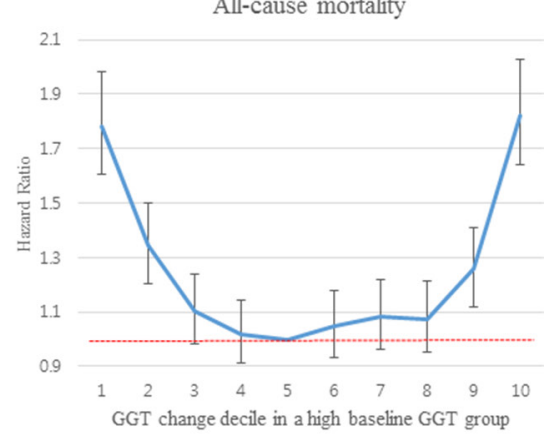

All-cause mortality

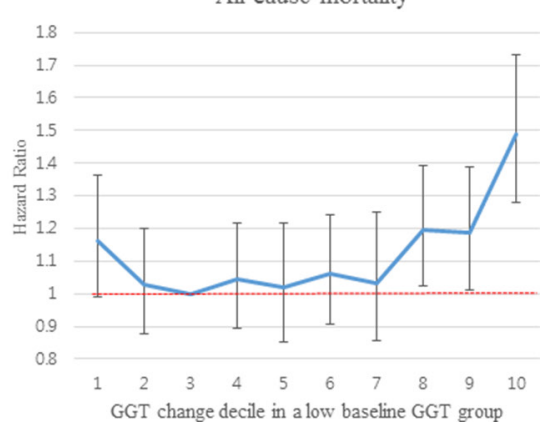

Figure 2 Associations ${ }^{\text {a }}$ between the deciles of changes in liver enzyme levels over a 4-year period and all-cause mortality, stratified by the median value of each baseline liver enzyme level. ${ }^{\text {HR }} \mathrm{H}$ s were estimated using Cox proportional hazard models adjusted for age, sex, household income decile, smoking status, alcohol consumption, physical activity, body mass index, systolic and diastolic blood pressure, fasting glucose levels, and history of heart disease, stroke and cancer. ALT, alanine aminotransferase; AST, aspartate aminotransferase; GGT, gamma glutamyltransferase.

enzyme levels over time, as well as baseline levels, can be used to predict mortality and assess risk by clinicians and public health practitioners. To our knowledge, this is the first study to demonstrate non-monotonic dose-response associations between changes in liver enzyme levels and mortality; further studies are warranted to confirm the findings.

In a study based on a representative US population data, lower baseline ALT levels were found to be associated with higher risks of cardiovascular disease, cancer and liver disease mortality, whereas higher ALT levels were only associated with a higher risk of liver disease mortality. ${ }^{7}$ In another study based on a representative sample of the US population, higher ALT levels were associated with a higher risk of liver disease mortality, whereas higher GGT levels were associated with higher risks of cancer, diabetes mellitus and liver disease mortality. ${ }^{15}$ A study using data from a prospective elderly cohort reported an association of higher AST levels with an increased risk of cancer mortality, as well as an association of higher GGT levels with an increased risk of cardiovascular disease mortality. ${ }^{8}$ Among patients with acute myocardial infarction who underwent percutaneous coronary intervention, ALT and AST levels were associated with stenosis diameter, an indicator of stenosis severity. ${ }^{29}$ Although the results of the present study were generally consistent with those of previous studies, ${ }^{7815}$ some inconsistencies were also found (eg, positive associations of baseline ALT levels with cardiovascular, cancer and diabetes mellitus mortality in the present study but not in previous studies).
These discrepancies might be attributable to factors such as differences in the accuracy of cause of death data, study populations, adjusted covariates and analytical methods. As the associations of baseline and changes in liver enzyme levels with cause-specific mortality have not been thoroughly investigated, additional studies are needed, particularly those using changes in liver enzyme levels as explanatory variables.

Serum liver enzyme levels may increase in response to various factors, including liver damage and cell destruction (eg, hepatocytes, biliary epithelium and other cells of organs such as the heart, skeletal muscle and kidney), ${ }^{1}$ and may decrease in response to factors such as age and frailty-related reductions in liver size and blood circulation. $^{9} 10 \quad 30$ Therefore, changes (both increases and decreases) in liver enzyme levels over time may reflect these conditions related to the deterioration of liver function and could thus be associated with a higher risk of mortality.

The present study has some limitations. First, although the NHIS-HEALS provides information on serum ALT, AST and GGT levels, data from other standard liver panel tests, such as albumin, alkaline phosphatase, and conjugated and unconjugated bilirubin levels, are not available. This limits our ability to assess liver function comprehensively. Second, although the National Health Screening Program was performed at designated healthcare institutions meeting the quality standards, liver enzyme levels were analysed by different laboratories with a different sensitivity and specificity, leading to potential 
information bias. Third, the present study used data that were not primarily collected for the purpose of research. Therefore, information on sociodemographic factors, lifestyles, medical histories and family histories is insufficient, leading to the possibility of residual confounding. Fourth, although common liver disease, such as nonalcoholic fatty liver disease, could increase liver enzyme levels $^{31}$ and mortality, ${ }^{32-34}$ specific mechanisms underlying the association between liver enzyme levels and mortality could not be identified thoroughly.

However, the present study also has notable strengths. First, to our knowledge, this is the first study to report non-monotonic dose-response associations between changes in liver enzyme levels over time and mortality. Second, we used a large-scale cohort constructed from national administration data, which has a negligible follow-up loss. The large sample size $(n=484472)$ of the present study allowed us to evaluate the potential associations with sufficient power. Third, we identified the dates and causes of death using a national database maintained by Statistics Korea, which covers all individuals residing in the Republic of Korea. The accuracy of the recorded causes of death in this database is considered high $(>90 \%) .^{35}$

\section{CONCLUSIONS}

We found non-linear associations of the baseline liver enzyme levels and their changes over time with risks of mortality. The results of the present study suggest that changes in liver enzyme levels, as well as baseline levels, can be used to predict health outcomes such as mortality and to assess risk in clinical and public health settings.

\section{Author affiliations}

${ }^{1}$ Division of Public Health and Preventive Medicine, Seoul National University Hospital, Seoul, Republic of Korea

${ }^{2}$ Department of Preventive Medicine, Seoul National University College of Medicine, Seoul, Republic of Korea

${ }^{3}$ Veterans Health Service Medical Center, Seoul, Republic of Korea

${ }^{4}$ Department of Forensic Medicine, Seoul National University College of Medicine, Seoul, Republic of Korea

Acknowledgements We would like to thank the National Health Insurance Service for their cooperation. We also would like to thank all those who planned, administered, conducted and participated in the National Health Screening Program.

Contributors K-NK, JJ, HKS, CHK, HK and YJK contributed to the conception and design of the study. K-NK conducted statistical analyses and wrote the initial manuscript. JJ, HKS, CHK, HK and YJK reviewed and revised the manuscript. All authors read and approved the final manuscript.

Funding This work was supported by Seoul National University Hospital and the National Health Insurance Service of the Republic of Korea.

Disclaimer The views in this study are those of the authors and are not necessarily those of Seoul National University Hospital or the NationalHealth Insurance Service of the Republic of Korea.

Competing interests None declared.

Patient consent for publication Not required.

Ethics approval The study protocol was reviewed and approved by the Institutional Review Board of Seoul National University Hospital (IRB no. E-1804-045-936).
Provenance and peer review Not commissioned; externally peer reviewed.

Data sharing statement The National Health Insurance Service-National Health Screening Cohort (NHIS-HEALS), which is used in the present study, is a deidentified cohort released to researchers by the NHIS for the purpose of public research. The data sets are provided to researchers after the study protocols are approved by the institutional review board of the researcher's institute and by the NHIS. Researchers can request the data sets through the website (https://nhiss. nhis.or.kr/bd/ay/bdaya001iv.do).

Open access This is an open access article distributed in accordance with the Creative Commons Attribution Non Commercial (CC BY-NC 4.0) license, which permits others to distribute, remix, adapt, build upon this work non-commercially, and license their derivative works on different terms, provided the original work is properly cited, appropriate credit is given, any changes made indicated, and the use is non-commercial. See: http://creativecommons.org/licenses/by-nc/4.0/.

\section{REFERENCES}

1. Green RM, Flamm S. AGA technical review on the evaluation of liver chemistry tests. Gastroenterology 2002;123:1367-84.

2. Gowda S, Desai PB, Hull VV, et al. A review on laboratory liver function tests. Pan Afr Med J 2009;3:17.

3. Kunutsor SK, Apekey TA, Seddoh D, et al. Liver enzymes and risk of all-cause mortality in general populations: a systematic review and meta-analysis. Int J Epidemiol 2014;43:187-201.

4. Kunutsor SK, Apekey TA, Khan H. Liver enzymes and risk of cardiovascular disease in the general population: a meta-analysis of prospective cohort studies. Atherosclerosis 2014;236:7-17.

5. Schneider AL, Lazo M, Ndumele CE, et al. Liver enzymes, race, gender and diabetes risk: the Atherosclerosis Risk in Communities (ARIC) Study. Diabet Med 2013;30:926-33.

6. Kunutsor SK, Apekey TA, Van Hemelrijck M, et al. Gamma glutamyltransferase, alanine aminotransferase and risk of cancer: systematic review and meta-analysis. Int $J$ Cancer 2015;136:1162-70.

7. Ruhl CE, Everhart JE. The association of low serum alanine aminotransferase activity with mortality in the US population. Am J Epidemiol 2013;178:1702-11.

8. Koehler EM, Sanna D, Hansen BE, et al. Serum liver enzymes are associated with all-cause mortality in an elderly population. Liver Int 2014;34:296-304.

9. Deetman PE, Alkhalaf A, Landman GW, et al. Alanine aminotransferase and mortality in patients with type 2 diabetes (ZODIAC-38). Eur J Clin Invest 2015;45:807-14.

10. Dong MH, Bettencourt R, Brenner DA, et al. Serum levels of alanine aminotransferase decrease with age in longitudinal analysis. Clin Gastroenterol Hepatol 2012;10:285-90.

11. Seong SC, Kim YY, Park SK, et al. Cohort profile: the National Health Insurance Service-National Health Screening Cohort (NHIS-HEALS) in Korea. BMJ Open 2017;7:e016640.

12. Lee G, Choi S, Kim K, et al. Association of Hemoglobin Concentration and Its Change With Cardiovascular and All-Cause Mortality. J Am Heart Assoc 2018;7.

13. Shin WY, Lee T, Jeon DH, et al. Diabetes, Frequency of Exercise, and Mortality Over 12 Years: Analysis of the National Health Insurance Service-Health Screening (NHIS-HEALS) Database. J Korean Med Sci 2018;33:e60.

14. Shin WY, Kim HC, Lee T, et al. Combined effects of diabetes and low household income on mortality: a 12-year follow-up study of 505677 Korean adults. Diabet Med 2018;35:1345-54.

15. Ruhl CE, Everhart JE. Elevated serum alanine aminotransferase and gamma-glutamyltransferase and mortality in the United States population. Gastroenterology 2009;136:477-85.

16. Liu Z, Ning H, Que S, et al. Complex association between alanine aminotransferase activity and mortality in general population: a systematic review and meta-analysis of prospective studies. PLOS One 2014;9:e91410.

17. Williams KH, Sullivan DR, Nicholson GC, et al. Opposite associations between alanine aminotransferase and $\gamma$-glutamyl transferase levels and all-cause mortality in type 2 diabetes: Analysis of the Fenofibrate Intervention and Event Lowering in Diabetes (FIELD) study. Metabolism 2016;65:783-93.

18. Dignam JJ, Zhang Q, Kocherginsky M. The use and interpretation of competing risks regression models. Clin Cancer Res 2012;18:2301-8.

19. Noordzij M, Leffondré K, van Stralen KJ, et al. When do we need competing risks methods for survival analysis in nephrology? Nephrol Dial Transplant 2013;28:2670-7. 
20. Ford I, Mooijaart SP, Lloyd S, et al. The inverse relationship between alanine aminotransferase in the normal range and adverse cardiovascular and non-cardiovascular outcomes. Int J Epidemiol 2011:40:1530-8.

21. Kim HC, Nam CM, Jee SH, et al. Normal serum aminotransferase concentration and risk of mortality from liver diseases: prospective cohort study. BMJ 2004;328:983.

22. Nakamura $\mathrm{K}$, Okamura $\mathrm{T}$, Kanda $\mathrm{H}$, et al. The value of combining serum alanine aminotransferase levels and body mass index to predict mortality and medical costs: a 10-year follow-up study of National Health Insurance in Shiga, Japan. J Epidemiol 2006;16:15-20.

23. Ravel V, Streja E, Molnar MZ, et al. Association of aspartate aminotransferase with mortality in hemodialysis patients. Nephrol Dial Transplant 2016:31:814-22.

24. Pinkham CA, Krause KJ. Liver function tests and mortality in a cohort of life insurance applicants. J Insur Med N Y N 2009;41:170-7.

25. Goessling W, Massaro JM, Vasan RS, et al. Aminotransferase levels and 20-year risk of metabolic syndrome, diabetes, and cardiovascular disease. Gastroenterology 2008;135:1935-44.

26. Fulks M, Stout RL, Dolan VF. Using liver enzymes as screening tests to predict mortality risk. J Insur Med N Y N 2008;40:191-203.

27. Kälsch J, Bechmann LP, Heider D, et al. Normal liver enzymes are correlated with severity of metabolic syndrome in a large population based cohort. Sci Rep 2015;5:13058.
28. Bechmann LP, Hannivoort RA, Gerken G, et al. The interaction of hepatic lipid and glucose metabolism in liver diseases. $J$ Hepatol 2012;56:952-64.

29. Baars T, Neumann U, Jinawy M, et al. In Acute Myocardial Infarction Liver Parameters Are Associated With Stenosis Diameter. Medicine 2016;95:e2807.

30. Tan JL, Eastment JG, Poudel A, et al. Age-Related Changes in Hepatic Function: An Update on Implications for Drug Therapy. Drugs Aging 2015;32:999-1008.

31. Loria P, Adinolfi LE, Bellentani S, et al. Practice guidelines for the diagnosis and management of nonalcoholic fatty liver disease. A decalogue from the Italian Association for the Study of the Liver (AISF) Expert Committee. Dig Liver Dis 2010;42:272-82.

32. Italian Association for the Study of the Liver (AISF). AISF position paper on nonalcoholic fatty liver disease (NAFLD): Updates and future directions. Dig Liver Dis 2017;49:471-83.

33. Targher G, Byrne CD, Lonardo A, et al. Non-alcoholic fatty liver disease and risk of incident cardiovascular disease: A meta-analysis. $J$ Hepatol 2016;65:589-600.

34. Lonardo A, Romagnoli D. Gamma glutamyl transferase: A novel cardiovascular outfit for an old liver test. Indian J Med Res 2016:143:4-7.

35. Won TY, Kang BS, Th I, et al. The Study of Accuracy of Death Statistics. J Korean Soc Emerg Med 2007;18:256-62. 